\title{
Stress Level and Its Determinants among Staff (Doctors and Nurses) Working in the Critical Care Unit
}

\author{
Vishwanath C Patil ${ }^{1} \odot$, Sanjivani V Patil ${ }^{\circledR}$, Jignesh N Shah ${ }^{3} \odot$, Shivakumar S Iyer $^{4}$
}

\begin{abstract}
Background: Very few extensive studies regarding job stressors among doctors and nurses have been conducted in India. It is important to explore the workplace to understand various stressors that adversely affect the well-being of an individual and also affect health care and needs of patients and relatives. Considering this, the present study was planned to determine stress among doctors and nurses from the critical care unit (CCU) and to find the association of stress with selected variables.

Materials and methods: This observational cross-sectional study was conducted among all staff (doctors and nurses) from the CCU. Data were collected with a pilot-tested, predesigned, validated questionnaire using the Google survey tool consisting of sociodemographic details and the ICMR work stress questionnaire. Analysis of data was done with SPSS version 25.

Results: Of 105 participants, 57 (54.3\%) were doctors and 48 (45.7\%) were nurses. A total of $48.6 \%$ (51) of participants scored 32 of 64 , that is, managed stress very well, and $51.4 \%$ of participants (54) scored 65 of 95 , that is, having a reasonably safe level of stress, but certain areas need improvement.

Conclusion: Stress was significantly more among females and those who have sleep problems. No statistically significant difference was found between the level of stress and age, relationship with seniors, exercise, and comorbidities.

Keywords: Critical care unit, Determinants of stress, Stress.

Indian Journal of Critical Care Medicine (2021): 10.5005/jp-journals-10071-23949
\end{abstract}

\section{INTRODUCTION}

Stress is what mind and body experience while adopting continuously changing environment. Organizational stress includes harmful emotional and physical reactions which occur when worker's capabilities, needs, or resources do not fit to the job. ${ }^{1}$

Sources of stress at workplace and levels of satisfaction are extensively studied abroad, but very few studies assessing sociodemographic background as well as workplace-related domains catering different emotional and practical aspects of stress have been conducted in India among doctors and nurses. Some of the stressors in the intensive care unit (ICU) are related to routine patient care, emotional needs, and counseling, while others are linked to healthcare personnel, such as inexperienced staff, dealing with interpersonal communication. Some are related to the environment and organizational structure. ${ }^{2}$ Working in critical care units (CCUs) is challenging emotionally and physically for doctors and nurses. Every day they deal with suffering, grief, and death. Increased workload, growing occupational stress, and lack of support from family are major concerns in nursing. ${ }^{3}$ Several studies have identified different stressors in some ICU hospitals that may not be present in other ICU hospitals. ${ }^{4}$ Therefore, it is important to explore the workplace to assess various stress factors experienced by healthcare workers.

Exposure to stress among healthcare professionals can have various outcomes like anxiety, depression, sleep disturbances, posttraumatic stress disorder, impairment of immune function, increase in cardiovascular risk factors, disturbed relationships with family, and burnout. Knowledge about presence of stress is therefore important, and if found, should be given attention for timely intervention. Burnout syndromes and stress are associated with decreased quality of care, and high rate of absenteeism ultimately
1,3,4 Department of Critical Care Medicine, Bharati Vidyapeeth (Deemed to be University) Medical College, Pune, Maharashtra, India ${ }^{2}$ Department of Community Medicine, Bharati Vidyapeeth (Deemed to be University) Medical College, Pune, Maharashtra, India Corresponding Author: Vishwanath C Patil, Department of Critical Care Medicine, Bharati Vidyapeeth (Deemed to be University) Medical College, Pune, Maharashtra, India, Phone: +91 7743875088, e-mail: vishwanath629@yahoo.com

How to cite this article: Patil VC, Patil SV, Shah JN, lyer SS. Stress Level and Its Determinants among Staff (Doctors and Nurses) Working in the Critical Care Unit. Indian J Crit Care Med 2021;25(8):886-889.

Source of support: Nil

Conflict of interest: None

affects the healthcare sector. ${ }^{5}$ All these stressors can affect the wellbeing of clinicians as well as health care and needs of patients and relatives. This study results may help in identifying different stress factors and in undertaking appropriate interventions to overcome them in healthcare workers. Considering this, the present study is planned to determine stress levels among doctors and nurses from the CCU and to find the association of stress with sociodemographic and workplace-related variables.

\section{Materials and Methods}

This study was an observational cross-sectional study conducted at a tertiary care hospital of a private medical college with a 35-bedded multidisciplinary ICU having a good case mix of all medical and surgical specialties. The study participants were staff (doctors and nurses) from the CCU. Based on the prevalence of stress among doctors and nurses, $52 \%$ in a study conducted by 
Arunesh et al., ${ }^{6}$ the sample size was estimated considering $10 \%$ of absolute error at $95 \%$ confidence interval using the following formula: $n=4 p q / l^{2}$ where $p=52 \%$ and $I=10 \%$. Minimum sample size calculated was 99. All staff (doctors and nurses) from the CCU who gave consent to the study were included. Staff with less than 3-month experience were excluded from the study. Institutional ethical committee approval was obtained. After taking informed consent from participants, the aim of study was stated and the questionnaire was explained. The respondents were assured that their confidentiality would be maintained. Data were collected with a pilot-tested, validated questionnaire using the Google survey tool. The questionnaire consisted of structured questions with two sections:

Part A consisted of sociodemographic and workplace details, and Part B consisted of the ICMR work stress questionnaire, ${ }^{7}$ which had 32 questions and scored on 1/2/3/4 criteria as follows: never-1, sometimes-2, frequently-3, and always - 4 . Interpretation of scores is explained in Table 1.

\section{Data Analysis}

The obtained data were coded, tabulated, and analyzed with SPSS package version 25. Data were described with descriptive statistics. For qualitative variables, frequency and percentage were calculated, whereas for quantitative variables, mean and standard deviation were calculated. Chi-square test was used to find the association between two qualitative variables.

\section{Results}

A total of 105 doctors and nurses from the CCU of a tertiary care hospital participated in the study. Details are shown in Table 2. Of 105 participants, 57 (54.3\%) were doctors, and 48 (45.7\%) were nurses. Of the study population, $60 \%$ were below 30 years of age and $40 \%$ were above 30 years of age. Females constituted $57.1 \%$ of the study population, and $71.4 \%$ of the study population belonged to nuclear family. Mean age of study participants was $29.97 \pm 7.90$ years (minimum age: 21 years, maximum age: 54 years). Average working experience in the ICU was $4.23 \pm 5.81$ years. Mean working hours per week was found to be $44.29 \pm 19.20$ hours. Average night duties per week was $2 \pm 1.84$.

Distribution of study participants according to sleep pattern, exercise, and comorbidity is depicted in Table 3. Of the study population, $77.1 \%$ participants had problems with sleep pattern, $22.9 \%$ practiced regular exercise. Also, $1+4.3 \%$ had comorbidities, and $31.4 \%$ of participants were anxious about what is going to come during duty.

\section{Work-related Stress}

Of the study population, $48.6 \%$ (51) scored 32 of 64 , that is, managed stress very well. Too little stress can decrease stimulation, so strive

Table 1: Interpretation of stress score

\begin{tabular}{ll}
\hline Score & Interpretation \\
\hline 32 of 64 & $\begin{array}{l}\text { You manage your stress levels very well. Too little stress } \\
\text { can reduce stimulation, so strive to achieve the balance } \\
\text { between negative and positive stress. }\end{array}$ \\
65 of 95 & $\begin{array}{l}\text { You have a reasonably safe level of stress, but certain } \\
\text { areas need improvement } \\
96 \text { of 128 }\end{array}$ \\
& $\begin{array}{l}\text { Your level of stress is too high. You need to develop } \\
\text { new strategies to improve it. }\end{array}$ \\
\hline
\end{tabular}

Table 2: Sociodemographic details of study participants

\begin{tabular}{llll}
\hline SI. No & Category & Frequency & Percentage \\
\hline 1 & Age & & \\
& $<30$ years & 63 & 60 \\
2 & $>30$ years & 42 & 40 \\
& Gender & & \\
& Male & 45 & 42.9 \\
& Female & 60 & 57.1 \\
& Marital status & & \\
& Married & 54 & 51.4 \\
4 & Unmarried & 51 & 48.6 \\
& No. of children & & \\
& 1 & 3 & 2.9 \\
& 2 & 27 & 25.7 \\
5 & Type of family & & \\
& Joint & 30 & 28.6 \\
& Nuclear & 75 & 71.4 \\
& Role in ICU & & \\
& Doctor & 57 & 54.3 \\
& Nurse & 48 & 45.7 \\
\hline
\end{tabular}

Table 3: Sleep pattern, exercise, and comorbidities

\begin{tabular}{lcc}
\hline Category & Frequency & Percentage \\
\hline Do you face problem in sleep pattern? & & \\
Yes & 21 & 77.1 \\
No & & 22.9 \\
Do you exercise regularly? & 24 & 22.9 \\
Yes & 81 & 77.1 \\
No & & \\
Do you have any comorbidities & 15 & 14.3 \\
Yes & 90 & 85.7 \\
No & & \\
How do you feel before arriving for duty & 33 & 31.4 \\
Anxious about what is going to come & 3 & 2.9 \\
Do not feel like going but it is unavoidable & 31 & 48.6 \\
Do not think & 51 & 14.3 \\
Stressed out about coming hours & 15 & \\
\hline
\end{tabular}

to attain the balance between positive and negative stress, and $51.4 \%$ (54) scored 65 of 95 , that is, a reasonably safe level of stress, but certain areas require improvement.

Details of stress levels and demographic variables are shown in Table 4 and Figure 1. Stress was significantly more among females when compared to males ( $p=0.001)$. Stress was marginally more among married as compared to unmarried, but it was statistically not significant $(p=0.763)$.

Details about stress and role in ICU are depicted in Table 5. There was no statistically significant difference found between stress levels and role of healthcare worker in the ICU. Both doctors and nurses are equally stressed $(p=0.364)$.

Relationship between the work pattern and level of stress is shown in Table 5. Stress was significantly more among those who faced sleep problems (Fig. 2). There was no statistical difference found between stress and relationship with seniors, exercise, and presence of comorbidities. 
Table 4: Stress and sociodemographic variables

\begin{tabular}{|c|c|c|c|c|c|c|}
\hline \multirow{2}{*}{ Variable } & & \multicolumn{2}{|c|}{ Stress_category } & \multirow[b]{2}{*}{ Total } & \multirow[b]{2}{*}{ Chi-square value } & \multirow[b]{2}{*}{$p$ value } \\
\hline & & Safe stress & Moderate & & & \\
\hline \multirow{2}{*}{ Age } & $<30$ & 30 & 33 & 63 & \multirow{2}{*}{0.057} & \multirow{2}{*}{0.811} \\
\hline & $\geq 30$ & 21 & 21 & 42 & & \\
\hline \multirow{2}{*}{ Gender } & Male & 30 & 15 & 45 & \multirow{2}{*}{10.32} & \multirow{2}{*}{0.001} \\
\hline & Female & 21 & 39 & 60 & & \\
\hline \multirow[t]{2}{*}{ Marital status } & Married & 27 & 27 & 54 & \multirow{2}{*}{0.91} & \multirow{2}{*}{0.763} \\
\hline & Unmarried & 24 & 27 & 51 & & \\
\hline \multirow[t]{2}{*}{ Type of family } & Joint & 12 & 18 & 30 & & \\
\hline & Nuclear & 39 & 36 & 75 & 1.23 & 0.26 \\
\hline Total & & 51 & 54 & 105 & & \\
\hline
\end{tabular}

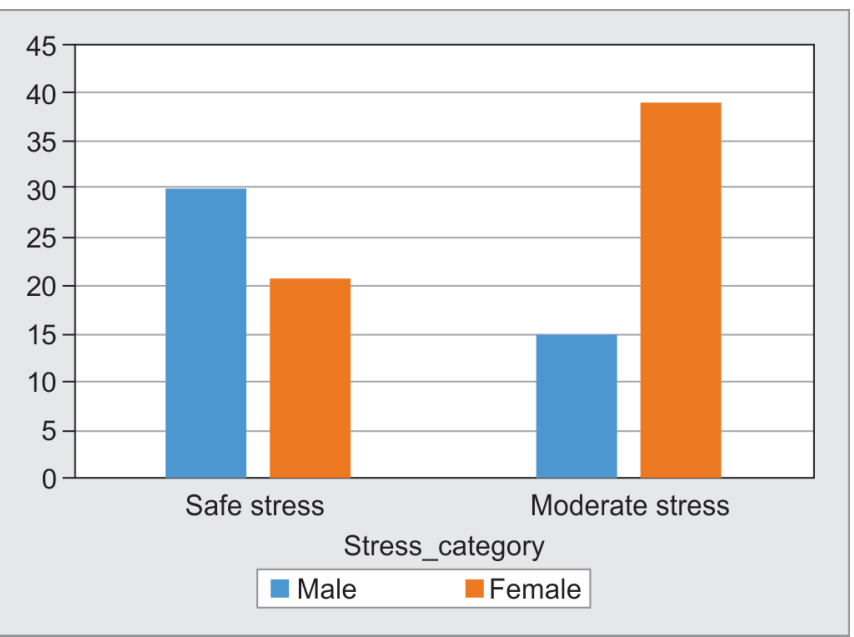

Fig. 1: Gender and stress

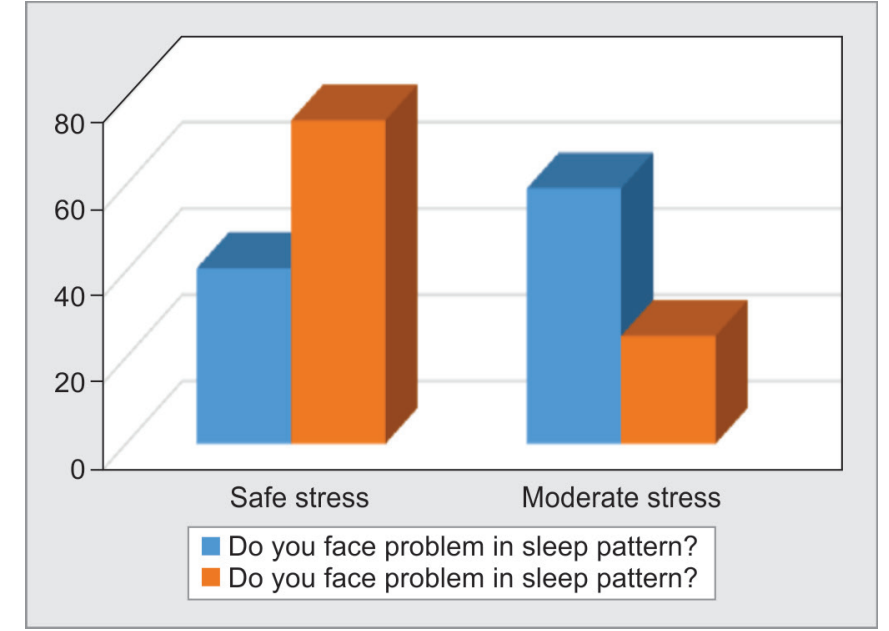

Fig. 2: Sleep pattern and stress

Table 5: Stress and work pattern

\begin{tabular}{|c|c|c|c|c|c|c|}
\hline & & Stress_c & ategory & & & \\
\hline & & Safe stress & Moderate & Total & Chi-square value & $p$ value \\
\hline Role in ICU & Doctor & 30 & 27 & 57 & 0.823 & 0.364 \\
\hline & Nurse & 21 & 27 & 48 & & \\
\hline Working relationship with seniors & Comfortable & 51 & 51 & 102 & 2.91 & 0.088 \\
\hline & Uncomfortable & 0 & 3 & 3 & & \\
\hline Do you face problem in sleep pattern? & Yes & 33 & 48 & 81 & 8.69 & 0.003 \\
\hline & No & 18 & 6 & 24 & & \\
\hline Do you exercise regularly? & Yes & 15 & 9 & 24 & 2.41 & 0.12 \\
\hline & No & 36 & 45 & 81 & & \\
\hline Do you have any comorbidities & Yes & 6 & 9 & 15 & 0.515 & 0.473 \\
\hline & No & 45 & 45 & 90 & & \\
\hline Total & & 51 & 54 & 105 & & \\
\hline
\end{tabular}

\section{Discussion}

A total of 105 doctors and nurses from the CCU of a tertiary care hospital participated in the study to assess stress and its determinants. Mean working hours per week was found to be $44.29 \pm 19.20$ hours, which corresponds to recommended hours. ${ }^{8}$

Of the study population, $51.4 \%$ were found to have a reasonably safe level of stress, but certain areas require improvement, which is in line with findings of the study by Arunesh et al. In a study conducted by Kushal et al. ${ }^{7}$ at a public sector super-specialty hospital, $41 \%$ of the study population had safe levels of stress. Kibria conducted a study to estimate the prevalence of stress among nursing staff from the ICU. Of them, $90 \%$ experienced stress. The differences may be due to differences in the scales and study settings (workplace-related factors). Stress was more in the age-group of less than 30 years, 
which may be because of less work experience and work overload. Stress was significantly high in females as compared to males. In a study conducted in north India by Sidiq et al., it was found that females (45.5\%) were more stressed as compared to males $(42.9 \%){ }^{9}$ This may be attributed to sociocultural and professional factors.

In this study, no statistically significant difference was found between stress and relationship with seniors, exercise, and presence of comorbidities, which is consistent with the study conducted by Kibria. ${ }^{10}$ Various studies have shown an association of interpersonal conflicts with seniors and colleagues and with patients and families, resulting in rise in risk of burnout. ${ }^{11,12}$

\section{Recommendations}

Based on the study findings, institutions can appoint a committee for healthcare workers to manage stress and arrange regular counseling sessions to avoid stage of burnout. Depending on study results, there can be a change in pattern and duration of working hours with provision of adequate rest after the night duty. This will help to frame policies by critical care societies and benchmarks to identify and solve causes of stress and burnout.

\section{OrCID}

Vishwanath C Patil @ ittps://orcid.org/0000-0002-0103-2210

Sanjivani V Patil @ https://orcid.org/0000-0003-4728-2407

Jignesh N Shah @ https://orcid.org/0000-0002-8812-8791

Shivakumar S lyer (1) https://orcid.org/0000-0001-5814-2691

\section{References}

1. Selye H. The stress of life. McGraw Hill: New York; 1976.

2. Bilodeau $C$. The nurse and her reactions to critical care nursing. Heart Lung 1993;2:358-363.

3. Jose T, Bhat SM. A descriptive study on stress and coping of nurses working in selected hospitals of Udupi and Mangalore districts Karnataka, India. IOSR J Nurs Health Sci 2013;3(1):10-18. DOI: 10.9790/1959-03111018.

4. Hussein J, Aniza I, Ahmad Taufik J. Factors associated with organizational stress among intensive care unit healthcare workers, in Somalia Hospital. Malaysian J Public Health Med 2012;12(1):57-66.

5. Embriaco N, Papazian L, Kentish-Barnes N, Pochard F, Azoulay E. Burnout syndrome among critical care healthcare workers. Curr Opin Crit Care 2007;13(5):482-488. DOI: 10.1097/MCC.0b013e3282efd28a.

6. Kumar A, Pore P, Gupta S, Wani AO. Level of stress and its determinants among Intensive Care Unit staff. Indian J Occup Environ Med 2016;20(3):129-132. DOI: 10.4103/0019-5278.203137.

7. Kushal A, Gupta SK, Mehta M, Singh MM. Study of stress among health care professionals: a systemic review. Int J Res Foundation Hosp Healthc Adm 2018;6(1):6-11. DOI: 10.5005/jp-journals-10035-1084.

8. International labour standards on working time. Available from: www.ilo.org.

9. Sidiq S, Mir AW, Ahmad J, Najib R, Andrabi B, Shah MA. Stress levels of doctors working in critical care units in a North Indian State. Int J Contemp Med Res 2017;4(3):625-628.

10. Md. Golam Kibria. Prevalence of stress and coping mechanism among staff nurses of intensive care unit in a selected hospital. Int J Neurosurg 2018;2(1):8-12. DOI: 10.11648/j.ijn.20180201.12.

11. Fumis RR, Amarante GA, de Fátima NA, Junior JM. Moral distress and its contribution to the development of burnout syndrome among critical care providers. Ann Intensive Care 2017;7:71. DOI: 10.1186/ s13613-017-0293-2.

12. Mealer M, Moss M. Moral distress in ICU nurses. Intensive Care Med 2016;42(10):1615-1617. DOI: 10.1007/s00134-016-4441-1. 